\title{
Morphometric diversity of reproductive structures in Hyptis suaveolens (L.) Poit.: An ethnomedicinal weed of Lamiaceae
}

\author{
Puja Rani Saha*, S. Sinha, R. K. Sinha \\ Department of Botany, Cytogenetics \& Plant Biotechnology Laboratory, Tripura University (A Central University), Suryamaninagar, \\ Tripura, India
}

Received: 30.03 .2017

Accepted: 03.05.2017

Published: 07.05.2017

*Address for correspondence:

Puja Rani Saha, Department of Botany,

Cytogenetics \& Plant Biotechnology Laboratory,

Tripura University (A Central University),

Suryamaninagar - 799022 ,

Tripura, India.

E-mail: pujars4@yahoo.com

\begin{abstract}
Hyptis suaveolens (L.) Poit. is an invasive ethnomedicinal weed of Lamiaceae. Morphometric studies of floral structures and seed dimorphism in the species were conducted. Detailed measurements of reproductive structures revealed moderate size variability in morphometric characters. This study reconfirms the existence of efficient pollination system in protandrous flower with carinal explosion in the species. Characteristic seed dimorphism prevailed with variable nutlet number and sizes in mature fruits. The inconsistent pattern of nutlet distribution in the fruit was grouped into five categories, and the most frequent was Category $A(2+2)$. Seed germination of $H$. suaveolens was phanerocotylar epigeal foliaceous type. Large seeds showed higher germination rate with $95 \%$ under lateritic soil condition whereas small seeds almost lacked germination. This study highlights the irregular and random nutlet distribution in fruits of $\mathrm{H}$. suaveolens adding to its diversity and fundamental reproductive behavior.
\end{abstract}

KEY WORDS: Ethnomedicinal weed, morphometry, Lamiaceae, reproductive structures

\section{INTRODUCTION}

Hyptis suaveolens (L.) Poit is an invasive weed species belonging to family Lamiaceae (Shenoy et al., 2009). The plant is an aromatic shrubby herb, commonly called pignut and locally known as Tukma in Tripura. It grows wild where soils are disturbed (Wulff, 1973). The species is highly adaptive in nature and widespread in distribution (Sharma and Raghubanshi, 2009). It is reported to have significant importance and utility as an ethnomedicinal resource in different regions of the world (Kirtikar and Basu, 1991; Beams, 1994; Chattarjee and Pakrashi, 1997; Pachkore et al., 2011). $H$. suaveolens is also characterized with certain floral specialities and represent an extraordinary pollination mechanism which is reflected in the phenomenon of carinal explosion. Both wind and insect-mediated pollination mechanisms operate to bring about self and cross-pollination in this species (Aluri, 1990). Sexual reproduction through insect-mediated crosspollination brings genetic diversity in this weed species (Aluri and Reddi, 1989). In spite of such impressive reproductive characteristics, the species is reported to produce low natural seed output (Aluri, 1990) and also exhibit the phenomenon of seed dimorphism (Wulff, 1973). Variation in seed size of $H$. suaveolens was reported which might be considered as an adaptive response to its particular niche (Mandal et al., 2008). Morpho-taxonomical description of the plant habit of H. suaveolens was reported by different workers (Deb, 1983; Raizada, 2006). However, there is very limited information on the morphometric investigation of floral reproductive structures of $H$. suaveolens. In addition, there are some contradictory reports on fruiting and germination aspects of the seeds in this species (Wulff, 1973; Mandal et al., 2008; Felippe et al., 1983; Deb, 1983; Matthew, 1995; Bhatt et al., 2012). In view of the above background, a detailed knowledge on the morphometry of the floral reproductive characters of H. suaveolens (L.) Poit has been necessitated to explore the nature of floral diversity of the species in a given population and its variability in dimorphic seeds along with seed germination. 


\section{MATERIALS AND METHODS}

H. suaveolens (L.) Poit. population growing wild in the open wastelands of Suryamaninagar area with geographical coordinates $23^{\circ} 45^{\prime} 47.7^{\prime \prime} \mathrm{N}$ and $91^{\circ} 16^{\prime} 02.5^{\prime \prime} \mathrm{E}$ and an altitude of $18 \mathrm{~m}$ was chosen for this study. Fresh flowering twigs were collected during early winter, and herbarium specimens were prepared and identified with the help of floristic literature (Deb, 1983). The herbarium specimen with accession number TU/B498 was submitted to the herbarium of the Department of Botany, Tripura University for reference. Nature of floral traits and seed characters was recorded during the reproductive and fruiting phase of the population. Fully matured flowers just before or during anthesis were used for detailed morphometric studies of the flower. Morphological observations and measurements of the different floral traits were taken in replicates of 20. Young and mature fruiting twigs were harvested during winter and fruits were carefully collected and studied. Fruits of $H$. suaveolens were studied with reference to the distribution of seeds, seed sizes, weight, and their variability. At least 100 fruits were randomly selected for measurement and analysis. Seed germination pattern was also investigated in four different treatments in replicates of three batches with 20 seeds in each.

\section{RESULTS AND DISCUSSION}

A comprehensive account on morphometry of reproductive traits including nature of fruits was studied in $H$. suaveolens growing wild in a given population. Phenological observation of the population revealed infrequent flowering as early as 07:30 morning and attaining its maximum at 09:00-14:00 h of daytime during early winter. The inflorescence was a panicle or short umbels with 3-5 blue purplish zygomorphic flowers in a cluster (Figure 1a). Morphometric measurements of the bilabiate corolla showed almost similar size ranging from $7.55 \pm 0.63 \mathrm{~mm}$ to $7.17 \pm 0.57 \mathrm{~mm}$. Characteristic pollen distribution was observed in the central white region of the upper lip of the corolla just after the carinal explosion (Aluri, 1990). The stamens were didynamous in nature having distinct long and short filaments with profuse hairs (Figure 1b). A collection of pollens around the staminal hairs was also recorded (Figure 1c) and found to act as a sink for pollens in efficient pollination system of the species as described by different workers (Aluri, 1990). The size variation in didynamous stamens was $1.581 \pm 0.134 \mathrm{~mm}$ and $1.286 \pm 0.181 \mathrm{~mm}$ in long and short filaments, respectively, with an average size of mature anther as $0.645 \pm 0.052 \mathrm{~mm}$ and $0.846 \pm$

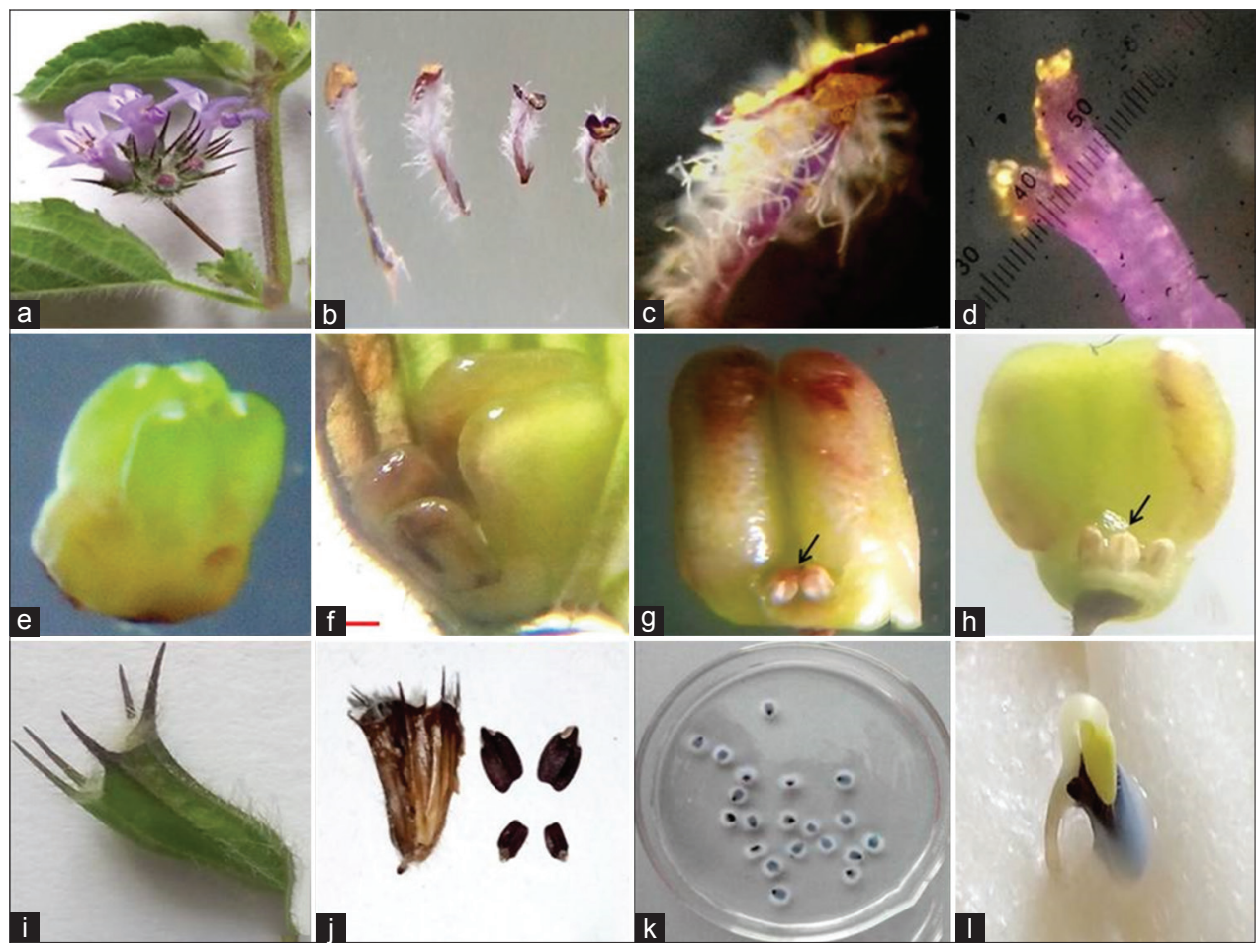

Figure 1: (a-l): Floral reproductive structures and seed germination in Hyptis suaveolens. (a) Zygomorphic flowers in a cluster. (b) Didynamous stamens with profuse white hairs. (c) Dehisced anther and pollens collecting in the staminal hairs. (d) A bifid stigmatic surface harvesting golden yellow pollens. (e) A four-partite ovary. (f) Post-fertilization change in ovary with unequal lobe formation, (-) bar $1 \mathrm{~mm}$. (g and h) Degenerating ovary $(\searrow)$. (i) A young fruiting calyx. (j) Mature schizocarpic fruit $(2+2)$ category. (k) Characteristic seed mucilage. (l) Phanerocotylar epigeal foliaceous type germination of large seed 
$0.113 \mathrm{~mm}(\mathrm{~L} \times \mathrm{B})$. Change in texture and color of the anther lobe from light brown color in buds to dark purple during its maturation and dehiscence was observed. Differential and early maturation of anthers were also recorded during the development of the whole floral reproductive structure. Infrequent anther dehiscence was recorded before the unfolding of colored petals. Significance of trapped pollens in the staminal hairs (Figure 1c) is found to be a natural adaptive device for maximum utilization of pollens during pollination. Thus, uniqueness of the stamen structures with respect to stigma and other floral parts could be attributed to an efficient mechanism for successful pollination and sexual reproduction as described by others (Ackerman, 2000; Dobson and Bergstrom, 2000; Lunau, 2000) in many taxa. Average size of four-partite ovary (Figure 1e) was $1.091 \pm 0.050 \mathrm{~mm}$ in length with a diameter of $0.772 \pm 0.078 \mathrm{~mm}$. Length and diameter of the style were $4.303 \pm 0.686 \mathrm{~mm}$ and $0.181 \pm 0.010 \mathrm{~mm}$, respectively, with a characteristic bifid stigmatic surface measuring $0.213 \pm 0.015 \mathrm{~mm}$ (Figure 1d). These findings on the organization of floral reproductive parts of the species also assure and reconfirm the previous records (Aluri, 1990; Aluri and Reddi, 1996).

The fruit of $H$. suaveolens was a schizocarpic type with persistent calyx (Figure 1i). Calyx enlarged to about $8 \mathrm{~mm}$ in length at fruit maturity and became papery, husky with whitish hairs. A pre-fertilized ovary was symmetrical and consisted of four equal parts (Figure 1e). However, the

Table 1: Distribution of large and small nutlets in mature schizocarpic fruits of Hyptis suaveolens (L.) Poit.

\begin{tabular}{lccccc}
\hline Fruit category (nutlets) & $\mathrm{A}(2+2)$ & $\mathrm{B}(3+1)$ & $\mathrm{C}(2+0)$ & $\mathrm{D}(1+2)$ & $\mathrm{E}(1+3)$ \\
\hline $\begin{array}{l}\text { Percentage of each fruit } \\
\text { category }\end{array}$ & 53.00 & 2.00 & 15.00 & 22.00 & 8.00 \\
\hline
\end{tabular}

In parentheses (distribution of large + small nutlet) ovary was transformed into asymmetrical nature of four parts during young fruit development (Figure 1f). Thus, significant post fertilization changes in the four-partite ovary structure leading to unequal lobe formation were observed. Seed dimorphism has been a common phenomenon in H. suaveolens (Wulff, 1973), but variation in nutlet distribution pattern in maturing fruits was recorded and grouped into five categories (Table 1). Fruit category "A" $(2+2)$ (Figure $1 \mathrm{j}$ ) was the usual type with a percentage of 53.00. Post-fertilization behavior displayed occasional degeneration in the young fruits (Figure $1 \mathrm{~g}$ and $1 \mathrm{~h}$ ) which may have also consequently lead to the diversity observed in nutlet distribution in the mature fruits. In spite of seed dimorphic nature, the variation in distribution pattern of dimorphic seeds among the fruits of this population (Tables 1 and 2) indicates diversity in seed production and fertility (Mandal et al., 2008). Morphologically, the nutlets were shield shaped. The large nutlet had no depressions on either side of the middle rib whereas the small nutlet had depressions. Variation in size and weight of nutlets revealed a significant difference between the large and small nutlet (Table 3). Seed germination tried with four different experimental treatments, viz., water soaked cotton pad, soil (lateritic), soilrite, and MS semisolid medium, revealed maximum seed germination (95\%) of large seeds in lateritic soil whereas small seeds did not respond at all (Table 2). Seed germination (Figure 1l) is phanerocotylar epigeal foliaceous type and produces characteristic mucilage when comes in contact with water (Figure 1k). This study highlights efficient germination of large seeds whereas no germination in small seeds indicating its abortive and infertile nature. This observation is in contradiction with the previous report (Mandal et al., 2008). However, small seed infertility may be associated with irregular function and development of the ovule (Nakamura, 1988; Martin and Lee, 1993). In-depth study on morpho-anatomical and biochemical aspects of

Table 2: Seed germination of $H$. suaveolens in different experimental treatments

\begin{tabular}{lcccc}
\hline Experimental treatment & Large seed $\left({ }^{*}\right.$ Mean \pm SD) & Germination percentage & Small seed (*Mean \pm SD) & Germination percentage \\
\hline Water soaked cotton & $17.67 \pm 1.53$ & 88.35 & - & - \\
Soil (lateritic) & $19.00 \pm 00$ & 95.00 & - & - \\
Soilrite & $15.33 \pm 1.15$ & 76.65 & - & - \\
MS semisolid medium & $11.67 \pm 0.58$ & 58.35 & - & - \\
\hline
\end{tabular}

* Mean of three replicates

Table 3: Morphometric characters of nutlet (seed) of Hyptis suaveolens

\begin{tabular}{|c|c|c|c|c|c|}
\hline \multicolumn{3}{|l|}{ Large nutlet } & \multicolumn{3}{|c|}{ Small nutlet } \\
\hline $\begin{array}{l}\text { Length } \\
\text { * Mean } \pm S D(\mathrm{~mm})\end{array}$ & $\begin{array}{c}\text { Diameter } \\
* \text { Mean } \pm S D(\mathrm{~mm})\end{array}$ & $\begin{array}{c}\text { Weight } \\
{ }^{\dagger} \text { Mean } \pm \text { SD (mg) }\end{array}$ & $\begin{array}{c}\text { Length } \\
* \text { Mean } \pm S D(\mathrm{~mm})\end{array}$ & $\begin{array}{c}\text { Diameter } \\
* \text { Mean } \pm S D(\mathrm{~mm})\end{array}$ & $\begin{array}{c}\text { Weight } \\
{ }^{\dagger} \text { Mean } \pm \text { SD (mg) }\end{array}$ \\
\hline $\begin{array}{l}3.36 \pm 0.26 \\
(2.80-3.80)\end{array}$ & $\begin{array}{l}2.23 \pm 0.23 \\
(1.90-2.90)\end{array}$ & $\begin{array}{l}5.85 \pm 0.81 \\
(5.00-7.00)\end{array}$ & $\begin{array}{l}1.96 \pm 0.25 \\
(1.00-2.20)\end{array}$ & $\begin{array}{l}0.99 \pm 0.14 \\
(0.50-1.20)\end{array}$ & $\begin{array}{l}1.02 \pm 0.11 \\
(1.00-1.25)\end{array}$ \\
\hline
\end{tabular}

* Mean of 100 observations; ${ }^{\dagger}$ Mean of 20 observations; in parentheses ( ) ranges of morphometric character. SD: Standard deviation 
pre- and post-ovular development of fertilization would be a useful step toward understanding seed dimorphism and its variability in $H$. suaveolens.

\section{ACKNOWLEDGMENTS}

The first author is highly grateful to University Grants Commission, Government of India for providing financial support to carry out the present part of my research work under the UGC-RET fellowship programme of Tripura University.

\section{REFERENCES}

Ackerman JD. Abiotic pollen and pollination: Ecological, functional, and evolutionary perspectives. Plant Syst Evol 2000;222:167-85.

Aluri JSR. The explosive pollination mechanism and mating system of the weedy Hyptis suaveolens (Lamiaceae). Plant Species Biol 1990;5:235-41.

Aluri JSR, Reddi CS. Pollination ecology of Hyptis suaveolens (Lamiaceae). Proc Indian Natl Sci Acad 1989;55:411-6.

Aluri JSR, Reddi CS. The explosive floral mechanism and pollination in the genus Hyptis (Lamiaceae). Proc Indian Natl Sci Acad 1996;B62:117-24.

Beams C. Atlas of Plants of MexicanTraditional Medicine. $1^{\text {st }}$ ed. Mexico: National Indigenous Institute; 1994.

Bhatt JR, Singh JS, Singh SP, Tripathi RS, Kohli RK. Invasive Alien Plants: An Ecological Appraisal for the Indian Subcontinent. Wallingford: CABI Publishers; 2012.p. 156.

Chatterjee A, Pakrashi SC. The Treatise on Indian Medicinal Plants. Vol. 1-5. New Delhi: PID, CSIR; 1997. p. 15.

Deb DB. The Flora of Tripura State. Vol. 2. New Delhi: Today and Tomorrow's Printers and Publ.; 1983. p. 323.

Dobson HEM, Bergstrom G. The ecology and evolution of pollen odors. Plant Syst Evol 2000;222:63-87.
Felippe GM, Polo M, Cardosa VJ, Figeiredo-Ribeiro RC. Germinacao da unidade de dispersao de erva invasora Hyptis suaveolens. An Sem Reg Ecol 1983;3:245-61.

Kirtikar KR, Basu BD. Indian Medicinal Plants. Vol. 3. India: Singh B and Singh MP Publ.; 1991. p. 2032.

Lunau K. The ecology and evolution of visual pollen signals. Plant Syst Evol 2000;222:89-111.

Mandal SM, Chakraborty D, Gupta K. Seed size variation: Influence on germination and subsequent seedling performance in Hyptis suaveolens (Lamiaceae). Res J Seed Sci 2008; 1:26-33.

Martin ME, Lee TD. Self pollination and resource availability affect ovule abortion in Cassia fasciculata (Caesalpiniaceae). Oecologia 1993;94:503-9.

Matthew KM. An Excursion Flora of Central Tamil Nadu, India. Rotterdam, Netherlands: A.A. Balkema/Rotterdam; 1995. p. 397-401.

Nakamura RR. Seed abortion and seed size variation within fruits of Phaseolus vulagris: Pollen donor and resource limitation effects. Am J Bot 1988;75:1003-10.

Pachkore GL, Dhale DA, Dharasurkar AN. Antimicrobial and phytochemical screening of Hyptis suaveolens (L Poit.) Lamiaceae. Int Mutidiscipl Res J 2011;1:1-3.

Raizada P. Ecological and vegetative characteristics of a potent invader, Hyptis suaveolens Poit. from India. Lyonia 2006;1:115-20.

Sharma GP, Raghubanshi AS. Plastic responses to different habitat type contribute to Hyptis suaveolens Poit. invasiveness in the dry deciduous forest of India. Ambio 2009;38:342-4.

Shenoy C, Patil MB, Kumar R. Wound healing activity of Hyptis suaveolens (L.) Poit (Lamiaceae). Int J Pharmatech Res 2009;1:737-44.

Wulff RD. Intrapopulational variation in the germination of seeds in Hyptis suaveolens. Ecology 1973;54:646-9. 